\title{
Inovasi Bisnis : Upaya Adaptasi UKM Werkudoro di Era Adaptasi Kebiasaan Baru
}

\author{
Kusnandar, Mohamad Harisudin, Nuning Setyowati, Raden Kunto Adi, Raden Rara Aulia Qonita* dan \\ Isti Khomah
}

Program Studi Agribisnis, Fakultas Pertanian, Universitas Sebelas Maret, Surakarta, Indonesia

Diterima: 27 Agustus 2020; Disetujui: 21 Oktober 2020

\begin{abstract}
Abstrak
Pandemi COVID-19 memiliki dampak yang besar terhadap berbagai sektor kehidupan, termasuk Usaha Kecil Menengah (UKM). Pemerintah membuat berbagai kebijakan, salah satunya adalah penerapan adaptasi kebiasaan baru. UKM harus beradaptasi dengan kondisi adaptasi kebiasaan baru. UKM Werkudoro adalah salah satu UKM di Kabupaten Sukoharjo. Untuk menghadapi kondisi adaptasi kebiasaan baru ini, UKM Werkudoro memiliki beberapa permasalahan. Permasalahannya adalah label kemasan tidak marketable, kemasan produk tidak marketable, membungkus kemasan dengan stapler dan UKM kurang berkembang. Metode yang digunakan adalah sosialisasi, introduksi, pelatihan dan pendampingan. Kegiatan pengabdian adalah perbaikan label kemasan yang marketable, mengintroduksikan kemasan marketable dengan standing pouch, mengintroduksikan sealer plastik, perbaikan dari spanduk produk dan pelatihan inovasi bisnis. Kegiatan pengabdian memberikan pengetahuan bagi UKM dan manfaat untuk adaptasi di dalam kondisi New Normal, sehingga UKM bertahan dan berkembang.
\end{abstract}

Kata kunci: adaptasi; bisnis; inovasi; kebiasaan baru; UKM

\section{Business Innovation: Adaptation Efforts of SMEs Werkudoro in the New Normal Era}

\begin{abstract}
The COVID-19 pandemic has a major impact on various sectors of life, including Small and Mid-size Enterprises (SMEs). The government makes various policies, one of which is the implementation of the New Normal. SMEs must adapt to New Normal conditions. SMEs Werkudoro is one of the SMEs in the Sukoharjo Regency. To face this New Normal condition, SMEs Werkudoro has several problems. The problem is that the packaging label is not marketable, product packaging is not marketable, wrap the packaging with stapler and SMEs are less developed. The method used are socialization, introduction, training and accompaniment. Community service activities are improvement marketable packaging labels, introducing marketable packaging with standing pouches, introducing of plastic sealers, repairing of product banner and business innovation training. Community service activities give knowledge for SMEs and benefits for adaptation in the New Normal condition, so they can survive and can develop.
\end{abstract}

Keywords: adaptation; business; innovation; new normal; SMEs

\footnotetext{
* Corresponding author: radenrara@staff.uns.ac.id

Cite this as: Kusnandar, Harisudin, M., Setyowati, N., Adi, R. K., Qonita, R. R. A., \& Khomah, I. (2020). Inovasi Bisnis : Upaya Adaptasi UKM Werkudoro di Era Adaptasi Kebiasaan Baru. AgriHealth: Journal of Agri-food, Nutrition and Public Health, 1(2), 81-88. doi: http://dx.doi.org/10.20961/agrihealth.v1i2.44034
} 


\section{PENDAHULUAN}

Pada tahun 2019, Usaha Mikro Kecil Menengah (UMKM) di Indonesia menjadi kontributor yang penting terhadap Produk Domestik Bruto (PDB). UMKM telah berkontribusi sebanyak $60 \%$ PDB dan berkontribusi sebesar $14 \%$ untuk jumlah total ekspor nasional. Namun, dalam kondisi saat ini sektor UMKM telah menjadi salah satu sektor yang mengalami keterpurukan akibat adanya pandemi COVID-19 di seluruh dunia (Susanti et al., 2020). Pandemi COVID-19 ini juga menyebabkan dampak yang begitu besar di berbagai tingkatan, namun dampak yang terberat dirasakan oleh Usaha Kecil Menengah (UKM). Pada kondisi sekarang ini, sangat banyak pelaku UMKM di sektor jasa dan produksi yang menghadapi berbagai tantangan akibat adanya pandemi COVID-19, antara lain terjadinya penurunan omset penjualan secara signifikan, penurunan jumlah konsumen yang membeli, kesulitan dalam memperoleh bahan baku dan hambatan dalam pemasaran produk (Rulandari et al., 2020).

Pandemi COVID-19 telah berdampak di segala sektor kehidupan. Pemerintah telah berupaya untuk menyelamatkan Negara Indonesia dengan membuat banyak kebijakan, mulai dari kebijakan Pembatasan Sosial Berskala Besar (PSBB) sampai dengan adanya penerapan tatanan kehidupan baru. Menurut Kumala dan Junaidi (2020) istilah tatanan kehidupan baru sering kali disebut sebagai "Era Adaptasi Kebiasaan Baru". Adaptasi kebiasaan baru merupakan suatu paradigma hidup baru yang memyatakan bahwa manusia diharuskan bisa berdamai dan berdampingan dengan COVID-19, yaitu dengan melaksanakan hidup sesuai dengan protokol kesehatan, contohnya seperti penerapan pola hidup sehat dan bersih serta selalu memakai masker selama vaksin belum ditemukan.

UKM yang ada di Indonesia harus dapat bertahan dengan memperhatikan adanya perubahan atau peralihan perilaku konsumen dan fenomena yang terjadi pada era pandemi COVID-19 ini, maka dengan memasuki masa adaptasi kebiasaan baru perlu menganalisa dan mengevaluasi usahanya agar dapat tetap bertahan di era adaptasi kebiasaan baru (Fahriyah dan Yoseph, 2020). Selain itu, UMKM perlu melakukan upaya adaptasi di era adaptasi kebiasaan baru ini, yaitu dengan melakukan inovasi bisnis. Menurut Winata (2017), inovasi bisnis adalah suatu bentuk keunggulan yang kompetitif yang dimiliki oleh suatu perusahaan apabila dibandingkan dengan perusahaan yang lainnya.

Menurut Sasono dan Rahmi (2014), suatu organisasi/perusahaan memerlukan inovasi untuk dapat maju dan berkembang. Supaya perusahaan bisa maju dan berkembang, maka perusahaan harus dikelola secara efektif. Hal seperti itulah yang disebut dengan manajemen inovasi. Manajemen inovasi ialah tentang bagaimana suatu perusahaan dapat mengelola berbagai inovasi yang ada di dalam perusahaan, yang meliputi perencanaan yang dibuat, proses yang dijalankan, sampai tahap implementasi dari perencanaan. Manajemen inovasi suatu perusahaan akan dapat membuka jalan bagi pertumbuhan perusahaan di masa yang akan datang serta menunjukkan adanya kesuksesan yang kompetitif.

Inovasi akan berubah menjadi hal yang penting dalam mengatasi berbagai perubahan. Inovasi yang dilaksanakan oleh perusahaan besar dapat memakai suatu lembaga penelitian atau sebuah mitra kerja, kondisi seperti itu terkadang sulit untuk dilaksanakan oleh UKM karena keterbatasan faktor modal. Namun inovasi harus tetap dilaksanakan oleh UKM, baik dalam bentuk inovasi pelayanan, inovasi produk, inovasi proses dan lain-lain. UKM harus dapat tampil beda dengan menampilkan ciri khas dan keunikan usahanya, supaya dapat dikenal oleh pasar. Tetap berada dan bertahan pada satu kondisi, tanpa menggali potensi yang dimiliki atau mencari potensi yang baru, sama artinya dengan membuat jebakan untuk perusahaannya agar jatuh (Sasono dan Rahmi, 2014). Lubis dan Lubis (2020) mengatakan bahwa keengganan pengusaha UKM berinvestasi dalam inovasi pada akhirnya akan membuat produktivitas usahanya cenderung lebih rendah. Berdasarkan kondisi tersebut, UKM perlu melakukan pengelolaan yang bagus dalam melaksanakan inovasi (Sasono dan Rahmi, 2014).

UKM Werkudoro merupakan UKM yang memproduksi karak dan sudah berdiri sejak tahun 2008 di Kecamatan Kartasura, Kabupaten Sukoharjo. Karak adalah suatu produk yang berasal dari beras yang dicampur dengan bumbu-bumbu dan dicetak dengan bentuk lempengan tipis, berbentuk bulat atau persegi. 
Biasanya harga karak cukup terjangkau oleh masyarakat, mudah didapatkan dan banyak disukai khususnya di Pulau Jawa. Karak banyak diproduksi oleh industri rumah tangga, dengan cara yang masih sederhana (Setyowati, 2010). Karak yang dibuat oleh UKM Werkudoro tidak menggunakan borax, sehingga memiliki rasa enak, gurih, renyah serta sehat. Menurut Nugraha et al. (2017), bahan dasar yang digunakan untuk membuat karak, akan menentukan kualitas karak yang dihasilkan. Beras (Oryza sativa Linn) merupakan bahan dasar yang digunakan untuk membuat karak.

Proses produksi adalah suatu kegiatan yang menciptakan atau menambah kegunaan suatu barang atau jasa dengan memakai faktorfaktor seperti bahan baku, tenaga kerja, mesin dan dana supaya menjadi lebih manfaat untuk memenuhi kebutuhan hidup manusia (Herawati dan Mulyani, 2016). Proses produksi 'Karak Super' dimulai dari beras dicuci bersih, kemudian direbus. Lalu bumbu-bumbu yang telah dihaluskan, dimasukkan ke dalam rebusan beras. Kemudian ditambahkan larutan tepung tapioka. Nasi yang berwujud adonan dikukus sampai matang, dihaluskan dengan cobek dalam kondisi masih hangat, kemudian dibentuk dadu dan dipotong tipis-tipis, dipres dan dijemur sampai kering. Setelah kering dilakukan penimbangan dan pengemasan.

Selama proses produksi, UKM Werkudoro menghadapi permasalahan, yaitu label kemasan masih sederhana, karena hanya berupa kertas putih yang dimasukkan ke dalam kemasan. Tehnik pengemasan karak belum menggunakan kemasan marketable karena masih menggunakan plastik biasa, sehingga kurang menarik. Proses packing kemasan masih menggunakan stapler, sehingga karak menjadi mudah terkena udara yang masuk ke dalam plastik yang akan menyebabkan karak menjadi lembab dan pada akhirnya kalau karak digoreng menjadi tidak renyah. Pemasaran UKM masih kurang berkembang secara pesat meskipun sudah melaksanakan kegiatan usahanya sejak tahun 2008.

Solusi dari permasalahan yang dihadapi UKM Werkudoro adalah dengan melakukan pendampingan dan memfasilitasi perbaikan label kemasan; mengintroduksikan kemasan marketable; mengintroduksikan sealer plastik dan melakukan pelatihan inovasi yang terdiri dari pelatihan inovasi pengembangan kemasan, desain kemasan dan pemasaran digital. Tujuan kegiatan Program Kemitraan Masyarakat ini adalah memberikan pengetahuan dan pendampingan kepada UKM Werkudoro dalam beradaptasi untuk menghadapi era adaptasi kebiasaan baru agar dapat tetap bertahan di masa pandemi COVID-19 dan berkembang dengan baik.

\section{BAHAN DAN METODE}

Kegiatan Program Kemitraan Masyarakat dilaksanakan di UKM Werkudoro yang beralamat di Desa Ngadirejo RT 4, RW 1, Kecamatan Kartasura, Kabupaten Sukoharjo. Kegiatan pengabdian di UKM Werkudoro dilakukan pada bulan Mei 2020. Pengabdian ini diawali dengan sosialisasi, perbaikan kemasan, introduksi, pelatihan dan juga pendampingan. Pelaksanaan sosialisasi dilakukan bertujuan untuk menginformasikan agenda kegiatan yang akan dilakukan serta waktu pelaksanaan.

Tahap perbaikan label kemasan yang marketable, dimulai dengan Tim Pengabdian mendesain label kemasan yang marketable, kemudian mendiskusikan dengan UKM Werkudoro untuk menyelaraskan ide dan keinginan. Setelah desain jadi kemudian mengintroduksikan kepada UKM.

Tahap introduksi kemasan yang marketable, Tim Pengabdian menawarkan berbagai jenis kemasan yang ada di pasaran, kemudian mendiskusikan kekurangan dan kelebihan masing-masing jenis kemasan. Setelah menemukan kemasan yang sesuai, kemudian mengintroduksikan kepada UKM.

Tahap introduksi sealer plastik, Tim Pengabdian menawarkan jenis sealer plastik yang tersedia di pasaran. Setelah UKM menentukan jenis sealer plastik yang sesuai kemudian mengintroduksikan kepada UKM tentang cara penggunaan dan perawatan sealer plastik tersebut.

Pelatihan inovasi bisnis dilaksanakan secara luring dan daring karena kondisi yang masih dalam pandemi COVID-19. Pelatihan secara luring hanya khusus UKM Werkudoro, sedangkan pelatihan daring ditujukan untuk UKM-UKM di Kabupaten Sukoharjo. Pelatihan inovasi bisnis meliputi pengembangan produk, desain kemasan dan pemasaran digital. 
Tahap pendampingan, dilakukan oleh Tim Pengabdian dengan memantau perkembangan UKM terkait dengan teknologi yang sudah diintroduksikan, kemudian dilanjutkan dengan pendampingan pada proses kemajuan UKM melalui inovasi bisnis yang dilakukan.

\section{HASIL DAN PEMBAHASAN}

\section{Sosialisasi}

Kegiatan sosialisasi yang dilakukan oleh Tim Pengabdian dimulai dengan melakukan silaturahmi ke UKM Werkudoro. Silaturahmi dilakukan oleh perwakilan anggota Tim Pengabdian karena kondisi masih dalam pandemi COVID-19. Sosialisasi bertujuan untuk memberikan informasi kepada UKM mitra terkait dengan kegiatan yang akan dilaksanakan (Gambar 1).

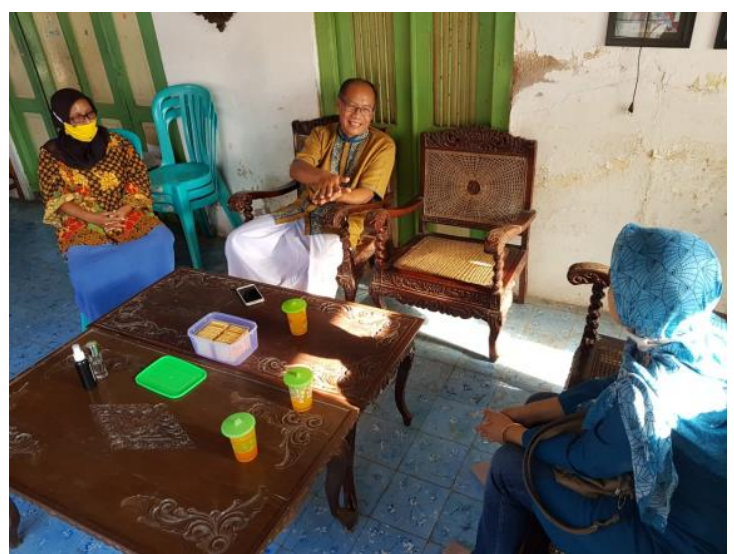

Gambar 1. Sosialisasi kegiatan ke UKM Werkudoro

\begin{abstract}
Introduksi kemasan marketable berupa kemasan standing pouch untuk 'Karak Super'

UKM Werkudoro sampai saat ini masih menggunakan kemasan yang belum marketable, karena hanya menggunakan plastik bening yang tipis. Untuk itu Tim Pengabdian melakukan perbaikan kemasan dengan mengintroduksikan dua macam kemasan plastik, yaitu: pertama, kemasan plastik bening dengan ukuran yang sama yaitu itu $17 \mathrm{~cm}$ x $30 \mathrm{~cm}$, dengan ketebalan 05. Menurut Tim Pengabdian, dengan ketebalan 05 diperkirakan sudah kuat dan apabila terjadi gesekan tidak menyebabkan plastik menjadi kusam. Gesekan tersebut dapat terjadi pada saat penataan produk yang ditumpuk atau pada saat produk dalam pengangkutan. Gambar 3 menunjukkan gambar kemasan plastik yang baru.
\end{abstract}

\section{Perbaikan label kemasan marketable dengan stiker berwarna dan lebih menarik}

UKM Werkudoro sudah menggunakan label kemasan, namun desainnya masih sangat sederhana. Label kemasan tersebut berupa kertas putih yang disablon dengan tinta berwarna biru, kemudian label kemasan tersebut dimasukkan ke dalam plastik. Berdasarkan kondisi tersebut Tim Pengabdian melakukan perbaikan label kemasan menjadi lebih marketable. Label kemasan tersebut terbuat dari stiker yang memiliki desain yang menarik dan nantinya direkatkan atau ditempel pada bagian luar kemasan plastik. Desain baru yang dibuat tidak meninggalkan ciri dari label kemasan yang lama, yaitu tetap menggunakan gambar wayang Werkudoro sebagai icon dari produk 'Karak Super' ini (Gambar 2).

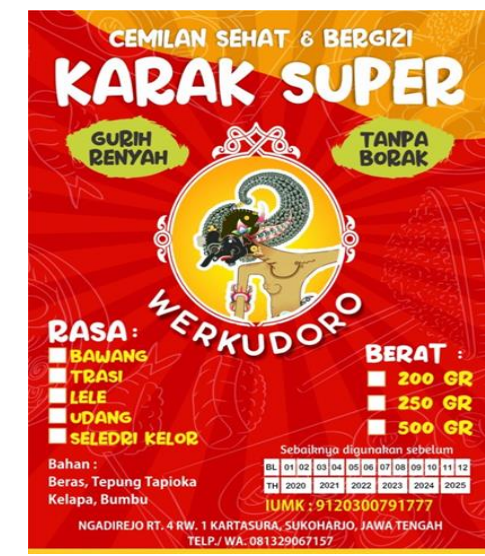

Gambar 2. Desain label kemasan yang diintroduksikan

Kedua, kemasan plastik dengan model standing pouch. Kemasan standing pouch merupakan salah satu jenis kemasan yang apabila diletakkan dapat berdiri vertikal. Kemasan ini memiliki ukuran $20 \mathrm{~cm}$ x $29 \mathrm{~cm} \times 0,12 \mathrm{~cm}$ dan memiliki sistem klip (zipper lock) dengan double sealer yang lebar. Kemasan standing pouch ini akan membuat produk 'Karak Super' menjadi lebih menarik untuk dilihat dan lebih elegan. Tim Pengabdian memilih kemasan standing pouch dengan pertimbangan sebagai berikut:

a) Kemasan terlihat lebih menarik, karena kemasan standing pouch memiliki model yang vertikal dan saat diletakkan dapat berdiri sehingga membuat daya tarik sendiri dibandingkan plastik biasa yang tidak bisa berdiri sendiri. 
b) Kemasan terlihat lebih kuat, karena plastik standing pouch yang digunakan cukup tebal maka akan cukup kuat untuk melindungi produk dari benturan-benturan yang menyebabkan produk menjadi rusak dan tidak menarik untuk dilihat.

c) Kemasan lebih praktis, karena kemasan ini memiliki bentuk yang simpel yang didukung dengan adanya penutup kemasan

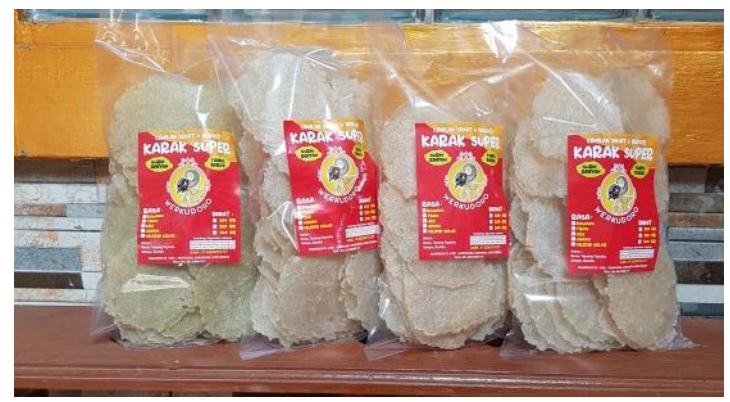

Gambar 3. Kemasan plastik 'Karak Super' yang baru

\section{Introduksi sealer plastik}

UKM Werkudoro dalam "mengunci" kemasan 'Karak Super' hanya menggunakan stapler. Untuk itu Tim Pengabdian mengintroduksikan sealer plastik. Sealer plastik ini berfungsi sebagai penutup kemasan produk agar menjadi lebih rapat sehingga 'Karak Super' menjadi lebih awet dan

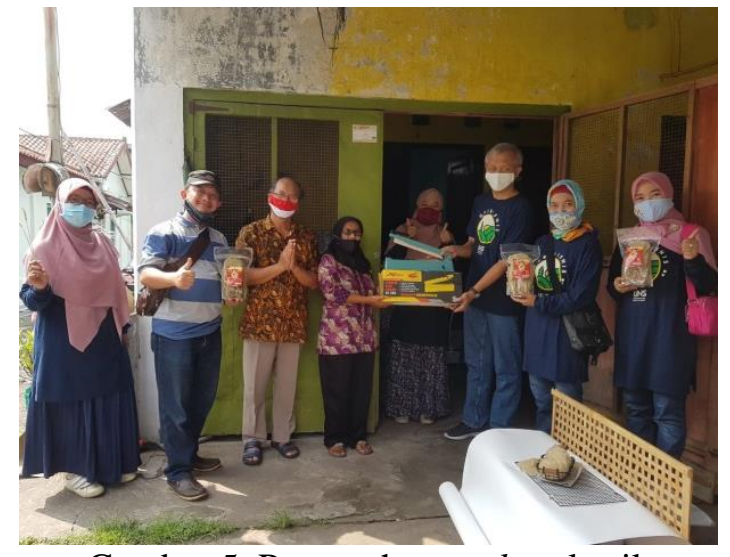

Gambar 5. Penyerahan sealer plastik

\section{Perbaikan spanduk produk bagi UKM Werkudoro}

UKM sudah menggunakan spanduk ukuran kecil, namun tidak menarik, warna sudah buram, terlihat kotor, pemasangan tidak sesuai dengan tembok tempat spanduk tersebut ditempelkan, sehingga tidak eye catching. Berdasarkan kondisi yang dilengkapi dengan zipper. Dengan adanya zipper tersebut dapat memberi kemudahan konsumen pada saat mengkonsumsi produk tersebut. Tutup kemasan yang mudah dibuka, namun tidak merusak produk yang ada di dalam kemasan. Contoh penggunaan kemasan standing pouch oleh UKM Werkudoro dapat dilihat pada Gambar 4.

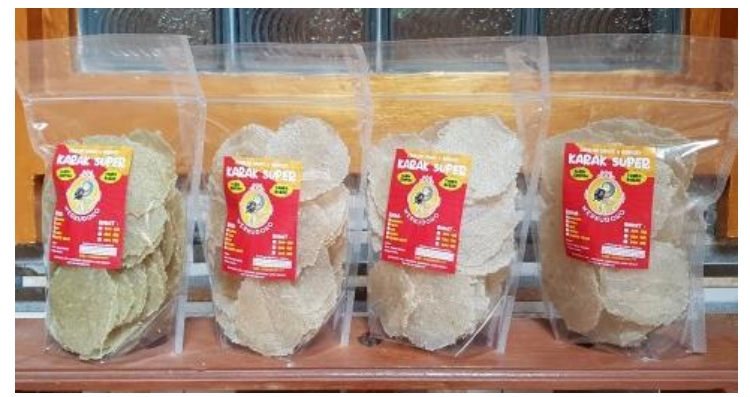

Gambar 4. Kemasan plastik standing pouch 'Karak Super' UKM Werkudoro

tahan lama, selain itu membuat tampilan kemasan menjadi lebih rapi. Sedangkan kemasan standing pouch, sealer plastik ini berfungsi sebagai "pengunci ganda" di atas zipper sehingga bisa berfungsi sebagai segel kemasan. Berikut ini adalah sealer plastik yang diintroduksikan dan penggunaannya (Gambar 5 dan Gambar 6).

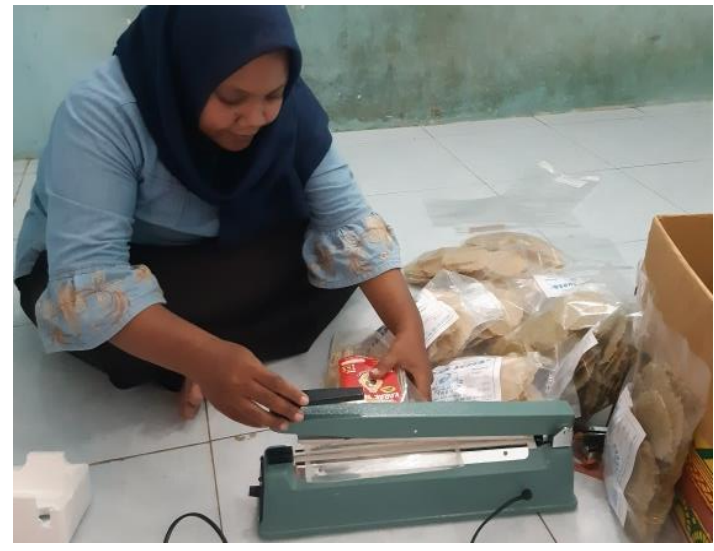

Gambar 6. Penggunaan sealer plastik

tersebut, Tim Pengabdian mendesain spanduk berbahan flexi dan memiliki ukuran lebar $50 \mathrm{~cm}$ dan tinggi $120 \mathrm{~cm}$. Desain spanduk disamakan dengan desain pada stiker yang digunakan untuk label kemasan. Berikut ini gambar desain spanduk dan pemasangan pada UKM Werkudoro (Gambar 7 dan Gambar 8): 


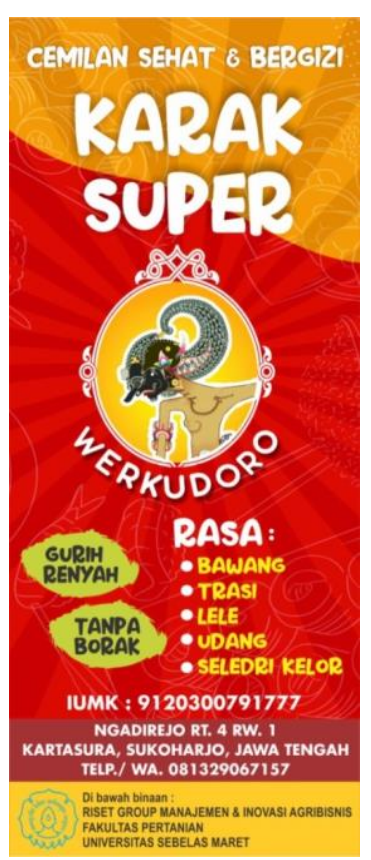

Gambar 7. Desain spanduk UKM Werkudoro

\section{Pelatihan inovasi bisnis}

Tim Pengabdian melakukan pelatihan inovasi secara luring dan daring. Pelatihan secara luring ditujukan untuk UKM Werkudoro, sedangkan pelatihan secara daring ditujukan untuk UKMUKM di Kabupaten Sukoharjo yang dilaksanakan pada tanggal 28 Juli 2020, pukul 09.00-12.00

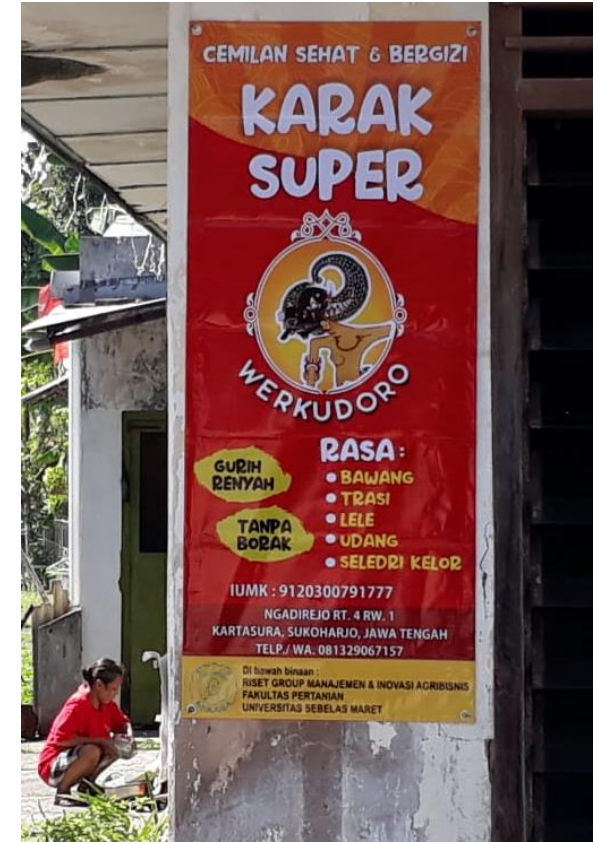

Gambar 8. Spanduk yang telah terpasang

WIB. Pelatihan inovasi bisnis meliputi: (1) pelatihan pengembangan produk; (2) pelatihan desain kemasan; (3) pelatihan pemasaran digital. Tim Pengabdian melakukan pelatihan secara daring kepada para pemilik UKM-UKM di Kabupaten Sukoharjo dengan menggunakan Aplikasi Zoom Meeting (Gambar 9).

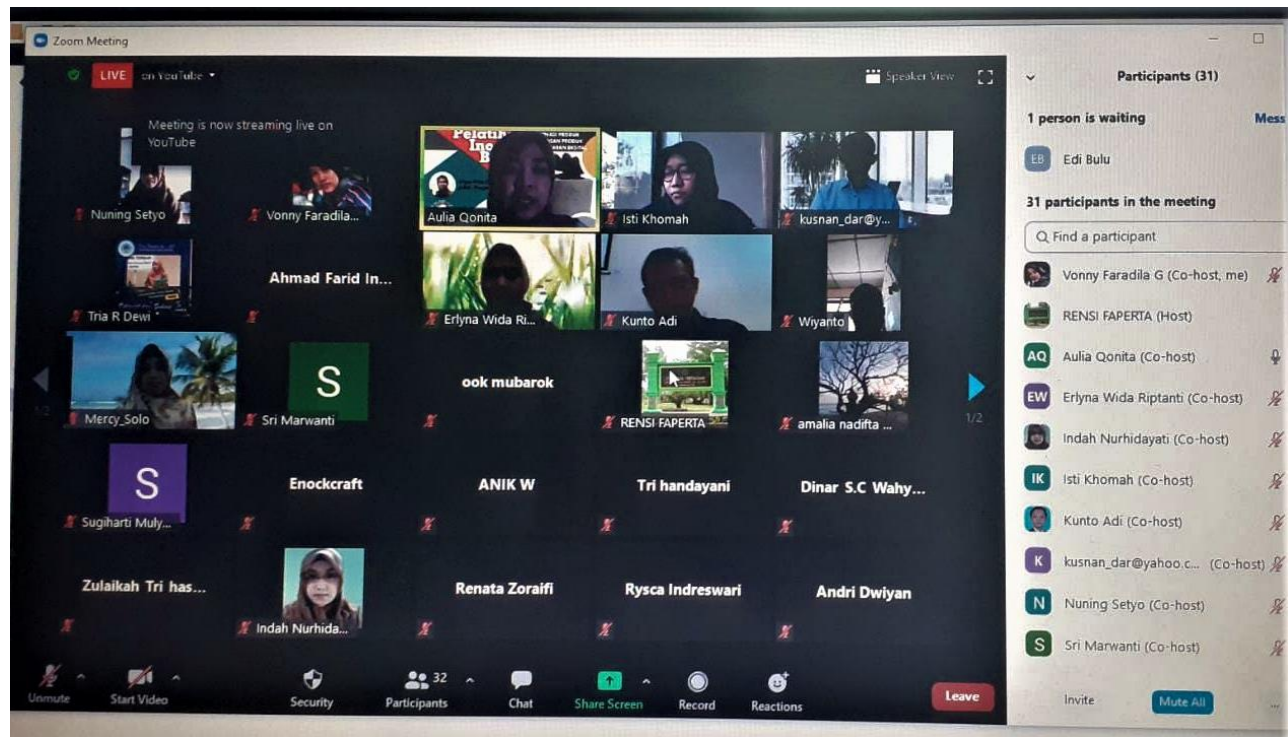

Gambar 9. Kegiatan pelatihan inovasi bisnis

\section{Pendampingan usaha 'Karak Super'}

Kegiatan pendampingan yang dilakukan bertujuan agar UKM Werkudoro dapat semakin mandiri, semakin maju dan berkembang seperti yang diharapkan. Meliputi: (1) Pendampingan penggunaan kemasan dan stiker marketable dilakukan agar UKM bisa menghadirkan produk 'Karak Super' yang bersifat biasa dan premium 
dengan perlakuan harga yang berbeda dan ditujukan untuk konsumen yang berbeda pula.

(2) Pendampingan perluasan pemasaran yaitu memberikan arahan dan menghubungkan UKM dengan para pemilik toko oleh-oleh atau dengan para reseller supaya penjualan meningkat.

\section{Indikator keberhasilan kegiatan}

Hasil evaluasi kegiatan pengabdian yang telah dilaksanakan disajikan dalam Tabel 1.

Tabel 1. Evaluasi hasil kegiatan pengabdian

\begin{tabular}{|c|c|c|c|}
\hline No. & Keterangan & Sebelum kegiatan pengabdian & Sesuadah kegiatan pengabdian \\
\hline 1. & $\begin{array}{l}\text { Perbaikan label } \\
\text { kemasan }\end{array}$ & $\begin{array}{l}\text { Label kemasan masih } \\
\text { sederhana dengan kertas HVS } \\
\text { dengan tinta biru }\end{array}$ & $\begin{array}{l}\text { Label kemasan lebih menarik dengan } \\
\text { kertas stiker dengan desain berwarna } \\
\text { warni }\end{array}$ \\
\hline 2. & $\begin{array}{l}\text { Perbaikan } \\
\text { kemasan } \\
\text { marketable }\end{array}$ & $\begin{array}{l}\text { Kemasan menggunakan plastik } \\
\text { tipis }\end{array}$ & $\begin{array}{l}\text { Kemasan menggunakan plastik ukuran } \\
17 \mathrm{~cm} \text { x } 30 \mathrm{~cm} \text { dengan ketebalan } 05 \text { dan } \\
\text { standing pouch ukuran } 20 \mathrm{~cm} \text { x } 29 \mathrm{~cm} \\
\times 0,12 \mathrm{~cm}\end{array}$ \\
\hline 3. & $\begin{array}{l}\text { Introduksi sealer } \\
\text { plastik }\end{array}$ & $\begin{array}{l}\text { Belum memiliki sealer plastik } \\
\text { untuk menutup kemasan }\end{array}$ & UKM memiliki 1 unit sealer plastik \\
\hline 4. & $\begin{array}{l}\text { Perbaikan spanduk } \\
\text { UKM }\end{array}$ & $\begin{array}{l}\text { Ukuran spanduk kecil, tidak } \\
\text { menarik, warna sudah buram, } \\
\text { kotor, pemasangan tidak pas } \\
\text { dengan tembok sehingga tidak } \\
\text { eye catching }\end{array}$ & $\begin{array}{l}\text { Terpasang spanduk dengan ukuran } 50 \\
\mathrm{~cm} \times 120 \mathrm{~cm} \text {, dengan desain yang } \\
\text { menarik, pemasangan pas dengan } \\
\text { tembok serta dapat dengan mudah } \\
\text { terlihat oleh para pengguna jalan }\end{array}$ \\
\hline 5. & $\begin{array}{lr}\text { Pelatihan } & \text { inovasi } \\
\text { bisnis } & \text { berupa } \\
\text { pengembangan } & \\
\text { produk, desain } \\
\text { kemasan dan } \\
\text { pemasaran digital }\end{array}$ & $\begin{array}{l}\text { - Varian rasa terbatas } \\
\text { - Desain kemasan masih } \\
\text { sederhana } \\
\text { - Pemasaran masih terbatas } \\
\text { secara offline }\end{array}$ & $\begin{array}{l}\text { - UKM memiliki rasa baru yaitu daun } \\
\text { seledri dan daun kelor } \\
\text { - UKM sudah menggunakan } \\
\text { kemasan dan stiker yang } \\
\text { marketable } \\
\text { - UKM mulai memasarkan secara } \\
\text { online }\end{array}$ \\
\hline
\end{tabular}

\section{Dampak dan manfaat kegiatan}

Kegiatan pengabdian telah memberikan dampak dan manfaat terhadap UKM, yaitu (1) Dapat meningkatkan pengetahuan UKM Werkudoro dalam melakukan pengemasan produk 'Karak Super' menggunakan kemasan dan label kemasan yang bersifat marketable, yang didukung dengan adanya sealer plastik sebagai pengunci atau penyegel kemasan. (2) Dapat meningkatkan pengetahuan UKM Werkudoro di dalam mengembangkan varian rasa produk 'Karak Super'. (3) Dapat meningkatkan pengetahuan UKM Werkudoro tentang cara dan teknik upload gambar di media sosial.

\section{KESIMPULAN}

Kegiatan pengabdian telah dilaksanakan dan dapat memberikan pengetahuan kepada UKM Werkudoro di dalam beradaptasi untuk menghadapi era adaptasi kebiasaan baru dengan cara mengemas 'Karak Super' sudah menggunakan kemasan marketable berupa plastik yang lebih tebal yaitu ukuran $17 \mathrm{~cm}$ x $30 \mathrm{~cm}$ dengan ketebalan 05 dan plastik standing pouch; UKM Werkudoro menutup kemasan sudah menggunakan sealer plastik; UKM Werkudoro sudah menggunakan label kemasan yang marketable yang ditempelkan pada bagian luar kemasan plastik; UKM Werkudoro mulai berkembang dengan adanya jalinan kerjasama dengan toko oleh-oleh, para reseller dan pemasaran secara online. Berdasarkan hal tersebut diharapkan UKM Werkudoro dapat tetap bertahan dan berkembang dengan baik.

\section{UCAPAN TERIMA KASIH}

Tim Pengabdian mengucapkan terima kasih kepada Lembaga Penelitian dan Pengabdian kepada Masyarakat (LPPM), Universitas Sebelas Maret yang telah memberikan Hibah Skim Pengabdian dengan Program Kemitraan Masyarakat Tahun 2020 (Surat Perjanjian Pelaksanaan Penugasan Program Pengabdian 
kepada Masyarakat Nomor: 453/UN27.21/ PN/2020). Tim Pengabdian juga mengucapkan terima kasih kepada UKM Werkudoro dan UKM lain yang telah berpartisipasi aktif dalam kegiatan pelatihan inovasi bisnis, sehingga dapat terlaksana dengan baik.

\section{DAFTAR PUSTAKA}

Fahriyah, A., \& Yoseph, R. (2020). Keunggulan kompetitif spesial sebagai strategi keberlanjutan UKM di Era New Normal. Prosiding Seminar Stiami, 7(2), 104-110. Tersedia dari http://ojs.stiami.ac.id/index.php/ PS/article/view/961/538

Herawati, H., \& Mulyani, D. (2016). Pengaruh kualitas bahan baku dan proses produksi terhadap kualitas produk pada UD. Tahu Rosydi Puspan Maron Probolinggo. Prosiding Seminar Nasional, 463-482. Tersedia dari https://jurnal.unej.ac.id/index.php/prosiding/a rticle/view/3677/2867

Kumala, R., \& Junaidi, A. (2020). Strategi bisnis dan pemanfaatan kebijakan pajak di masa pandemi COVID-19 dan Era New Normal (Studi kasus pelaku UKM marketplace). Prosiding Seminar Stiami, 7(2), 98-103. Tersedia dari https://ojs.stiami.ac.id/index.ph p/PS/article/view/960

Lubis, S. F., \& Lubis, A. F. (2020). Pengaruh pekerja keluarga dan peran inovasi terhadap produktivitas usaha di Indonesia. Jurnal Ekonomi dan Pembangunan Indonesia, 20(1), 111-132. https://doi.org/10.21002/jepi.v20i1. 1018
Nugraha, E. P., Karyantina, M., \& Kurniawati, L. (2016). Sodium tripolyphosphate (STPP) sebagai bahan pengganti bleng padat pada pembuatan karak dengan variasi jenis beras. Jurnal Teknologi Dan Industri Pangan, 1(2), 97-106. Tersedia dari http://ejurnal.unisri.ac. id/index.php/jtpr/article/view/1522

Rulandari, N. R., Rahmawati, N. F., \& Nurbaiti, D. (2020). Strategi komunikasi pemasaran usaha mikro kecil dan menengah pada Era New Normal. Prosiding Seminar Stiami, 7(2), 21-28. Tersedia dari http://ojs.stiami.ac.id/ index.php/PS/article/view/951/528

Sasono, E., \& Rahmi, Y. (2014). Manajemen inovasi pada Usaha Kecil Menengah. Jurnal STIE Semarang, 6(3), 74-90. Tersedia dari http://jurnal3.stiesemarang.ac.id/index.php/jur nal/article/view/122/95

Setyowati, A. (2010). Penambahan Natrium Tripolifosfat dan CMC (Carboxy Methyl Cellulose) pada pembuatan Karak. Jurnal AgriSains, 1(1), 40-49. Tersedia dari https://ejurnal.mercubuana-yogya.ac.id/index. php/Agrisains/article/view/19/16

Susanti, A., Istiyanto, B., \& Jalari, M. (2020). Strategi UKM pada masa pandemi. KANGMAS: Karya Ilmiah Pengabdian Masyarakat, 1(2), 67-74. https://doi.org/1 $0.37010 /$ kangmas.v1i2.50

Winata, E. (2017). Inovasi bisnis di bengkel dan modifikasi icon autoworks. Agora, 5(3), 1-7. Tersedia dari http://publication.petra.ac.id/ind ex.php/manajemen-bisnis/article/view/6088/5 586 